\title{
Accessory Mental Foramina Assessed by Cone-Beam Computed Tomography: Report of Unilateral and Bilateral Detection
}

\author{
Forámenes Mentales Accesorios Evaluados Mediante Tomografía \\ Computarizada Cone-Beam: Reporte de su Detección Unilateral y Bilateral
}

Ivonne Garay* \& Mario Cantín",**,****

\begin{abstract}
GARAY, I. \& CANTÍN, M. Accessory mental foramina assessed by cone-beam computed tomography: Report of unilateral and bilateral detection. Int. J. Morphol., 31(3):1104-1108, 2013.

SUMMARY: Accessory mental foramen (AMF) is a rare anatomical variation with particular importance in local anesthesia and surgical procedures, especially the placement of dental implants. We report the cases of two adult patients, which were referred for ConeBeam Computed tomography (CBCT) evaluation, which revealed the presence of three AMFs connected to the mandibular canal, one case with one AMF on the right side unilaterally, and another case was bilateral. The mean diameter measured for the AMFs was 1.23 $( \pm 0.45) \mathrm{mm}$, and the mean distance from the mandibular foramen to the AMF was $3.3( \pm 1.5) \mathrm{mm}$, with the AMF located in the premolar area superiorly or distally to the MF. CBCT is an effective tool for tridimensional assessment of AMF. A CBCT should be obtained prior to mandibular surgeries so that the presence of accessory mental foramen can be detected, and to avoid the occurrence of a neurosensory disturbance or hemorrhage. The AMF is a rare, but considering relevant anatomic variation, this structure should be kept in mind in dental practice.
\end{abstract}

KEY WORDS: Accessory mental foramen; Anatomical variation; Mental foramen; Cone-beam Computed tomography.

\section{INTRODUCTION}

The mental foramen is located on the anterolateral aspect of the mandible, through which the mental nerve emerges, a somatic afferent sensory branch of the alveolar inferior nerve. This nerve plays an important role in procedures in this area, such as administration of local anesthesia and surgical intervention.

In general, a human has a pair of mental foramina, a single foramen on either side. However, when it is double or multiple, and smaller than the mental foramen, the additional foramen is termed accessory mental foramen (AMF) (Sisman et al., 2012). An AMF foramen is reported to be rare, with prevalence ranging from 1.4 to $10 \%$ (Balcioglu \& Kocaelli, 2009). Bidimensional radiograph examinations, such as intraoral and panoramic radiographs, are limited and depend on the geometric projection of the structure (Mraiwa et al., 2003; Angelopoulos et al., 2008), and can underestimate the presence or extension of this variation and are not entirely reliable for presurgical planning (Katakami et al., 2008). Although panoramic radiography is generally the most common choice for presurgical planning, its limitations must be taken into consideration. AMFs are rarely observed with conventional radiography techniques, because the long axis of an AMF is generally less than $1.5 \mathrm{~mm}$, and it is difficult to recognize this structure (Sisman et al.).

With the recent marked progress in imaging modalities, nondestructive investigations should allow for precise observations, and tridimensional techniques can be very helpful for the detection of accessory foramina (Greenstein \& Tarnow, 2006; Imada et al., 2012). Cone Beam Computed tomography (CBCT) can help to obtain in-depth information on maxillofacial structures; particularly in the mandible; it is clinically significant to accurately identify the location of the mental foramen and AMFs (Igarashi et al., 2004). Naitoh et al. (2009) and Katakami et al. classified accessory foramina according to their continuity with the mandibular canal. According to these reports, an AMF showing a connection with the mandibular canal, and some authors

\footnotetext{
* CIMA Gruop, Department of Integral Adult Dentistry, Faculty of Dentistry, Universidad de La Frontera, Temuco, Chile.

** Doctoral Program in Morphological Science, Faculty of Medicine, Universidad de La Frontera, Temuco, Chile.

${ }^{* * *}$ Center of Research in Biomedical Sciences, Universidad Autónoma de Chile, Temuco, Chile.
} 
found an AMF using preoperative CBCT (Igarashi et al.), with few reported cases of bilateral AMF.

The evaluations of AMF are clinically important in endodontic treatments and surgical procedures such as dental implant insertion, bone grafting and mandibular anterior segmented osteotomy (Sisman et al.). The detection of AMFs may reduce the rates of haemorrhage, postoperative pain and paralysis risk in surgical procedures (Naitoh et al.).

The purpose of this article is to present two cases with unilateral and bilateral AMFs seen on CBCT and discuss the relevance of this anatomical variation.

\section{CASE REPORTS}

Two patients were referred to the Department of Oral and Maxillofacial Radiology in the Faculty of Dentistry at Universidad de La Frontera for Cone-Beam Computed Tomography (CBCT) evaluation. First case was a 44-year-old female referred to evaluate the mandibular second right premolar root, and the second case was a 60-year-old man referred to evaluate the mandible, prior to possible insertion of dental implants. The intended areas for the implants were the mandible right and left premolars.

Reconstructed three-dimensional CBCT images revealed the presence of two openings in the cortical bone of the mandible in both cases. A reconstructed sagittal image showed that accessory openings leading to the buccal mandibular canal. The images demonstrated the presence of an obvious connection to the mandibular canal, confirming that the openings were an AMF.

A total of three AMFs were found on CBCT images; one case was unilateral (female patient), with one AMF on the right side (Fig. 1), and one case was bilateral (male patient) (Fig. 2).

The mean diameter measured on CBCT for the AMFs was $1.23( \pm 0.45) \mathrm{mm}$, and mean diameter of MF was $3.4( \pm 0.7) \mathrm{mm}$. The mean ratio between their diameters (AMF diameter/MF diameter) was 0.4 . The mean vertical distance

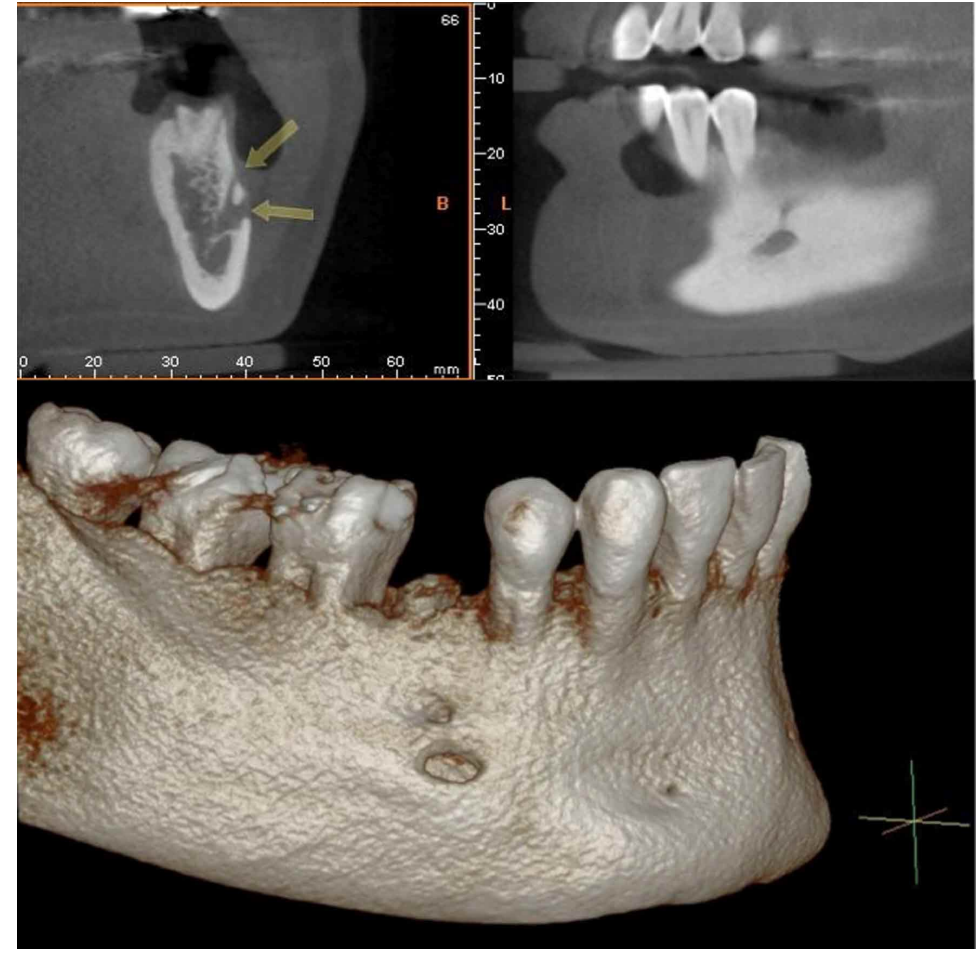

Fig. 1. The accessory mental foramen and canal on the female patient's right side are seen in the CBCT coronal cross-section. Images show the mental foramen and accessory mental foramen (arrows). An inferior image shows the Three-dimensional with the location of the accessory mental foramen.

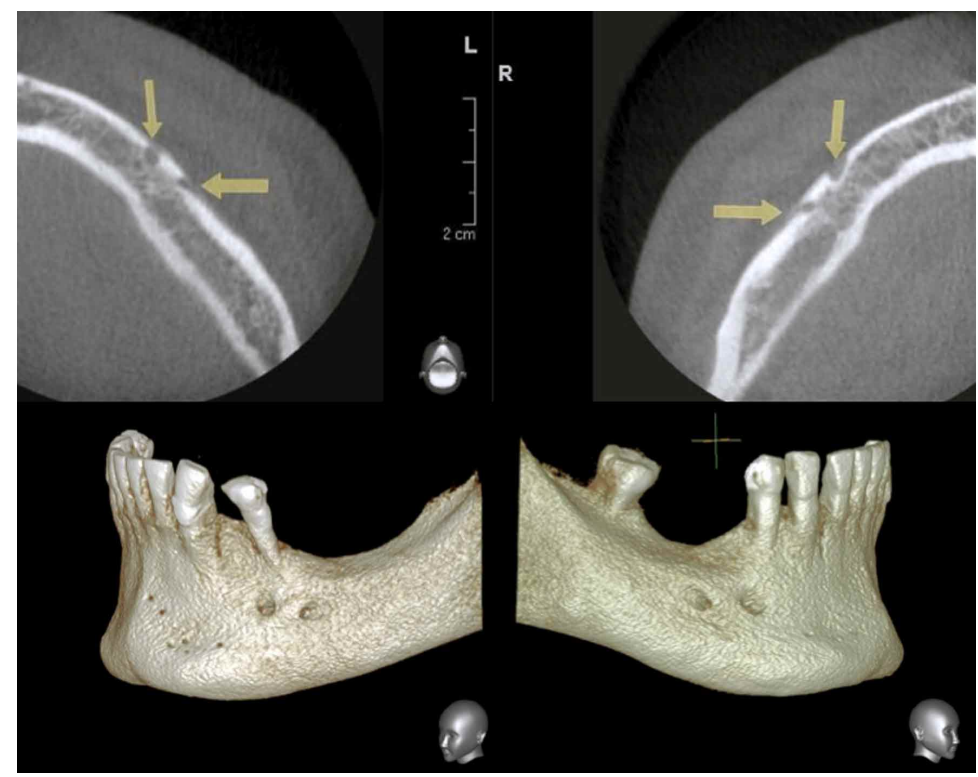

Fig. 2. The accessory mental foramen on the male patient's right and left sides are seen in axial CBCT images, and show the mental foramen and accessory mental foramen (arrows). Inferior images show the Three-dimensional reconstruction with the location of the accessory mental foramen in each side.

from the MF to the AMF was $3.3( \pm 1.5) \mathrm{mm}$, with the AMF located right above or distally to the MF (Table I). 
Table I. Diameter of accessory mental foramina (AMF) and mental foramen (MF), AMF/MF diameter ratio and distance, and description about AMF location related to MF and to the teeth observed on cone-beam computed tomography (CBCT) images.

\begin{tabular}{lccc}
\hline & Case 1 & Case 2 Right Side & Case 2 Left Side \\
\hline MF diamete $\mathrm{r}(\mathrm{mm})$ & 2.8 & 4.2 & 3.2 \\
AMF diameter $(\mathrm{mm})$ & 0.8 & 1.7 & 1.2 \\
AMF/MF diameter ratio & 0.29 & 0.4 & 0.38 \\
AMF-MF distance $(\mathrm{mm})$ & 1.5 & 4.4 & 3.9 \\
Location related to MF & Right above & Distally & Distally \\
Location related to teeth & Between premolars & Below 2nd premolar & Below 2nd premolar \\
\hline
\end{tabular}

\section{DISCUSSION}

Anatomical variations in the mandible, in the form of accessory foramen located in the region surrounding the mental foramen and showing a connection with the mandibular canal is defined as AMF (Sisman et al.), can cause complications in successful anesthesia and surgical procedures if not properly identified (Kaufman et al., 2000; Imada et al.). The most accurate way to diagnose the presence of AMF is by visual inspection during dissection or by examination of dry mandibles (Singh \& Srivastav, 2010). However, this method is not applicable to patient management. This report demonstrates the presence of AMF, their diameter, distance to the MF, and location in relation to the MF and to teeth on $\mathrm{CBCT}$ images.

AMFs have been reported to be detected by macroscopic investigations on dry skulls, investigations with plane radiography (periapical and panoramic radiography), and computed tomography. As far as we are concerned, unbiased radiological interpretation of an AMF is possible on CBCT images since the disadvantages of low image quality, low magnification, and distortionare overcome. Some previous anatomic studies showed the occurrence of the AMF in $6.62-12.5 \%$ of cases (Hanihara \& Ishida, 2001). Imaging modalities that provide non invasive tridimensional data of sections of the human body have enhanced new studies on anatomic features and variations, contributing to safer presurgical planning (Suazo et al., 2011). On previous CT or CBCT, AMF presence ranged from 2\% to $10.7 \%$ (Katakami et al.; Naitoh et al.; Sisman et al.). In our cases, AMF could not be detected on panoramic view of CBCT (Imada et al.).

Our data study (mean MF and AMF, AMF/MF ratio, vertical and horizontal position), comparing with cadaveric and others CBCT examinations show similar results (Imada et al.), without gender differences (Balcioglu \& Kocaelli). The mean diameter of AMF in this study was $0.93 \mathrm{~mm}$, consistent with the previous study that reported a mean diameter of $0.8-1.5 \mathrm{~mm}$. The mean long axis of the AMF ranged from $0.8-1.7 \mathrm{~mm}$, in accordance with previous CTbased studies (Sisman et al.), and the mean long axis was found to be 1.23 (SD 0.45) $\mathrm{mm}$. The ratio between diameters of ipsilateral foramina (AMF/MF) was 0.4 , showing that AMF was significantly smaller than MF, hence, discriminating between them was not difficult. Previous studies have reported AMF diameters equal to or greater than half of the MF diameter in $37 \%$ of cases, with the maximum AMF/MF ratio reaching 0.99 , meaning that in some cases, the AMF had virtually the same diameter as the MF (Oliveira-Santos et al., 2011). The mean diameter of MF found on our study, was $2.34 \mathrm{~mm}$, consistent with the results of anatomical studies that found the mean diameter to range from 2.38-2.64 mm (Oguz \& Bozkir, 2002), always greater than AMF.

In the cases reported here, two AMF were located under the second premolar. This finding is consistent with the findings of previous study in which the highest percentage (42.3\%) of AMF were found under the second premolar (Balcioglu \& Kocaelli). The position found in the bilateral case coincides with the most frequently reported, in the distal region of mental foramen (frequency of $41 \%$ ), while the upper position, found unilaterally, reached a frequency of $6 \%$. Bilateral AMFs are rare and have been described in $6-8 \%$ of the cases of presence of AMF, corresponding to approximately $0.53 \%$ of total population (Katakami et al.; Oliveira-Santos et al.)

The presence of AMF may be explained because it seems that mandibular neurovascularization may show historic variation comparing human Neolithic, Medieval and 19-20th century mandible samples showing that neurovascularization is becoming more complex over time (Liang et al., 2009). In addition, during the embryonic 
development, the mental foramen is incomplete until the 12th gestational week, when the mental nerve separates into several fasciculi at that site, suggesting that separation of the mental nerve earlier than the formation of the mental foramen could be a reason for the AMF formation (Naitoh et al.).

In patients presenting accessory innervation due to presence of AMF, anesthetic failure is expected to occur in $10-20 \%$ of cases if only the inferior alveolar nerve is blocked (Boronat Lopez \& Penarrocha Diago, 2006), and reports of neurosensory disturbances during surgical procedures involving the mandible are not rare. Sensory dysfunction due to nerve damage can occur if the inferior alveolar nerve, mental nerve or its accessory branches are damaged (Greenstein \& Tarnow). Therefore, an AMF and its potential variations may give way to important neurovascular anatomic structures, and their detection is fundamental to safe and successful surgical procedures.
If the AMF cannot be clearly identified on panoramic radiographs, a CBCT should be utilized to determine the existence, extent and location of the AMF (Fuakami et al., 2011; Thakur et al., 2011), and it is the best tool in order to avoid neurovascular complications during dental implant and bone graft placement, regional anesthesia, surgical correction of jaw deformities and periapical surgery, and probability of the existence of an accessory mental foramen should be kept in mind in dentistry (Balcioglu \& Kocaelli).

\section{CONCLUSION}

The results of this report demonstrate that $\mathrm{CBCT}$ is a useful tool for the anatomic assessment of the MF region and particularly in the detection of AMF. It is essential to be aware of the possibility of these anatomical variations already when planning surgery and when viewing the pre-operative radiological examination.

GARAY, I. \& CANTÍN, M. Forámenes mentales accesorios evaluados mediante tomografía computarizada Cone-Beam: Reporte de su detección unilateral y bilateral. Int. J. Morphol., 31(3):1104-1108, 2013.

RESUMEN: El foramen mental accesorio (FMA) es una variación anatómica rara, con especial importancia en la anestesia local y los procedimientos quirúrgicos, sobre todo la colocación de implantes dentales. Presentamos los casos de dos pacientes adultos, los cuales fueron derivados para ser evaluados mediante Tomografía Computarizada Cone-Beam (TCCB), la cual reveló la presencia de tres FMA conectados al canal mandibular, un caso con FMA en el lado derecho unilateral y el otro caso bilateralmente. El diámetro medio de los FMAs fue $1,23( \pm 0,45) \mathrm{mm}$, y la distancia media desde el foramen mental a los FMAs fue 3,3 $( \pm 1,5)$ mm, con el FMA situado en la zona premolar, superior o distal al foramen mental. La TCCB es una herramienta eficaz para la evaluación tridimensional del FMA. Este examen debe ser obtenido antes de las cirugías mandibulares, de modo que la presencia del FMA pueda ser detectado, y que la ocurrencia de una alteración neurosensorial o hemorragia pueda ser evitado. El FMA es una inusual pero relevante variación anatómica que se debe tener en cuenta en la práctica clínica y quirúrgica.

Cone-Beam.

PALABRAS CLAVE: Foramen mental accesorio; Variación anatómica; Foramen mental; Tomografía computarizada

\section{REFERENCES}

Angelopoulos, C.; Thomas, S. L.; Hechler, S.; Parissis, N. \& Hlavacek, M. Comparison between digital panoramic radiography and cone-beam computed tomography for the identification of the mandibular canal as part of presurgical dental implant assessment. J. Oral Maxillofac. Surg., 66(10):2130-5, 2008 .

Balcioglu, H. A. \& Kocaelli, H. Accessory mental foramen. N. Am. J. Med. Sci., 1(6):314-5, 2009.

Boronat López, A. \& Peñarrocha Diago, M. Failure of locoregional anesthesia in dental practice. Review of the literature. Med. Oral Patol. Oral Cir. Bucal, 11(6):E510-3, 2006.
Fuakami, K.; Shiozaki, K.; Mishima, A.; Shimoda, S.; Hamada, Y. \& Kobayashi, K. Detection of buccal perimandibular neurovascularisation associated with accessory foramina using limited cone-beam computed tomography and gross anatomy. Surg. Radiol. Anat., 33(2):141-6, 2011.

Greenstein, G. \& Tarnow, D. The mental foramen and nerve: clinical and anatomical factors related to dental implant placement: a literature review. J. Periodontol., 77(12):1933-43, 2006.

Hanihara, T. \& Ishida, H. Frequency variations of discrete cranial traits in major human populations. IV. Vessel and nerve related variations. J. Anat., 199(Pt 3):273-87, 2001. 
Igarashi, C.; Kobayashi, K.; Yamamoto, A.; Morita, Y. \& Tanaka, M. Double mental foramina of the mandible on computed tomography images: a case report. Oral Radiol., 20(2):68-71, 2004.

Imada, T. S.; Fernandes, L. M.; Centurion, B. S.; de Oliveira-Santos, C.; Honório, H. M. \& Rubira-Bullen, I. R. Accessory mental foramina: prevalence, position and diameter assessed by cone-beam computed tomography and digital panoramic radiographs. Clin. Oral Implants Res., doi: 10.1111/clr.12066, 2012.

Kaufman, E.; Serman, N. J. \& Wang, P. D. Bilateral mandibular accessory foramina and canals: a case report and review of the literature. Dentomaxillofac. Radiol., 29(3):170-5, 2000.

Katakami, K.; Mishima, A.; Shiozaki, K.; Shimoda, S.; Hamada, Y. \& Kobayashi, K. Characteristics of accessory mental foramina observed on limited cone-beam computed tomography images. J. Endod., 34(12):1441-5, 2008.

Liang, X.; Jacobs, R.; Corpas, L. S.; Semal, P. \& Lambrichts, I. Chronologic and geographic variability of neurovascular structures in the human mandible. Forensic Sci. Int., 190(13):24-32, 2009.

Mraiwa, N.; Jacobs, R.; Moerman, P.; Lambrichts, I.; van Steenberghe, D. \& Quirynen, M. Presence and course of the incisive canal in the human mandibular interforaminal region: two-dimensional imaging versus anatomical observations. Surg. Radiol. Anat., 25(5-6):416-23, 2003.

Naitoh, M.; Hiraiwa, Y.; Aimiya, H.; Gotoh, K. \& Ariji, E. Accessory mental foramen assessment using cone-beam computed tomography. Oral Surg. Oral Med. Oral Pathol. Oral Radiol. Endod., 107(2):289-94, 2009.

Oguz, O. \& Bozkir, M. G. Evaluation of location of mandibular and mental foramina in dry, young, adult human male, dentulous mandibles. West Indian Med. J., 51(1):14-6, 2002.

Oliveira-Santos, C.; Capelozza, A. L.; Dezzoti, M. S.; Fischer, C. M.; Poleti, M. L. \& Rubira-Bullen, I. R. Visibility of the mandibular canal on CBCT cross-sectional images. J. Appl. Oral Sci., 19(3):240-3, 2011.

Sisman, Y.; Sahman, H.; Sekerci, A.; Tokmak, T. T.; Aksu, Y. \& Mavili, E. Detection and characterization of the mandibular accessory buccal foramen using CT. Dentomaxillofac. Radiol., 41(7):558-63, 2012.

Singh, R. \& Srivastav, A. K. Study of Position, Shape, Size and Incidence of Mental Foramenand Accessory Mental Foramen in Indian Adult Human Skulls. Int. J. Morphol., 28(4):1141-6, 2010.

Suazo, G. I.; Zavando, M. D. \& Cantín, L. M. Canal mandibular accesorio: análisis de su prevalencia y aspecto imagenológico. Av. Odontostomat., 27(2):85-90, 2011.
Thakur, G.; Thomas, S.; Thayil, S. C. \& Nair, P. P. Accessory mental foramen: a rare anatomical finding. BMJ Case Rep., doi:10.1136/bcr.09.2010.3326, 2011.

\author{
Correspondence to: \\ Mario Cantín \\ Department of Integral Dentistry \\ Faculty of Dentistry \\ Universidad de La Frontera \\ Manuel Montt 112, Temuco \\ CHILE
}

Phone + 560452325574

Email: mario.cantin@ufrontera.cl

Received: 06-05-2013

Accepted: 22-07-2013 